\title{
Franz Schubert en Màrius Torres
}

\author{
Franz Schubert in Màrius Torres
}

\author{
Ferran Carbó \\ Universitat de València \\ ferran.carbo@uv.es
}

\begin{abstract}
This study reviews the presence of the composer Franz Schubert in five poems by Màrius Torres. These texts were written between 1933 and 1938, while Torres consolidated and evolved as a poet. The writer from Lleida performed musical scores with the piano and the Austrian composer, through his Lieder, became a model, something that is evident in the different ways in which transtextuality is present, not only between the songs' lyrics and Torres' poems, but also between the musical compositions and these same poems. This study analyzes how, on the one hand, Schubert's Lieder "Der Erlkönig" and "Der Tod und das Mädchen", with texts by Johann Wolfgang Goethe and Matthias Claudius respectively, work as a starting point - or hypotext - for three poems by the Catalan poet, "El rei dels verns", "La Mort i el Jove" and "Paraules de la Mort", thus converted into hypertexts. On the other hand, Torres' two poems "Adverbis de Schubert" and "Mai" refer to the Austrian composer from the intertextual relationship with the poem "Jamais" by Alfred de Musset. At the same time Torres mentions Schubert and the Lied "Ständchen" with text by Ludwig Rellstab in "Adverbis de Schubert", but the Catalan poet hides Schubert's copresence in "Mai".
\end{abstract}

Keywords: Lieder, Franz Schubert, poetry, Màrius Torres, transtextuality

Com "un poeta líric" (Torres, 2010a, p. 322) es va autodefinir Màrius Torres en la seua carta dirigida a Carles Riba, datada el 14 de juliol de 1942, pocs mesos abans de la mort. L'autor nascut a Lleida havia assenyalat, a la carta del 9 de desembre de 1941 enviada a Joan Sales, alguns trets del llenguatge poètic com sonoritat, musicalitat ideal, melodia contínua, modulacions noves... (Torres, 2010a, p. 318; Sales, 2014); és a dir, aspectes tendents a convertir-lo en una forma expressiva pròxima a la música (Bou, 1989, p. 85). I fins i tot a la carta del 12 d'agost de 1937, dirigida a Mercè Fi- 
gueras, el poeta indicava, com un pas més, que "estaria molt content si pogués posar música als meus versos" (Torres \& Figueras, 2018, p. 118).

Mentre es trobava ingressat al sanatori de Puig d'Olena, entre els anys 1935 i 1942, Torres va dedicar una part del seu temps no sols a escriure poesia, sinó també a interpretar peces musicals amb piano, tant al piano del sanatori com al que hi havia a Mas Blanc (Prats, 1986, 2010). En la producció poètica s'esmenten nombrosos compositors: així Couperin, Corelli, Händel, Bach, Mozart, Beethoven, Schubert o Schumann, entre d'altres (Carbó, 1995); noms que palesen l'atracció per la música de teclat per a clavecí i piano i també pels músics del barroc, el classicisme i el romanticisme. Fins i tot, sobretot l'últim any de la seua vida, va gosar de compondre algunes partitures, per a textos de Paul Verlaine, Jaufré Rudel, Bernart de Ventadorn i Peire Cardenal (Boixareu, 1968; Klein, 2017, 2018). La idea d'aproximar-se al Lied era evident (Rabaseda i Matas, 2010; Lleó, 2018).

Distintes formes de transtextualitat, com ara la intertextualitat (Kristeva, 1969; Genette, 1982), la hipertextualitat (Genette, 1982), la paratextualitat (Genette, 1987) i també la interdiscursivitat (Segre, 1982) o la interartisticitat i la intermedialitat (Koralova, 2008) són aspectes essencials de la seua escriptura. Així ho confirma amb claredat la presència de Franz Schubert i dels textos literaris que es cantaven en alguns dels seus Lieder. De fet, Mercè Figueras, anomenada Mahalta en algunes de les cançons de Torres (Carbó, 2020), a la carta del 21 de juny de 1937 li va escriure: “parlaràs en vers amb la fluïdesa d'un Schubert” (Torres \& Figueras, 2018, p. 86-87).

\section{1. "DER ERLKÖNIG"}

Els dos primers reculls que va escriure, abans de l'ingrés al sanatori, foren Primers poemes, entre els anys 1927 i 1929, i Música de cambra $i$ altres poemes, entre 1931 i 1934, els quals van romandre inèdits fins que alguns textos es van seleccionar a la primera edició de Poesies (1947), feta per Joan Sales a Coyoacán dins Quaderns de l'Exili.

Cal observar que el setè text d'aquest recull de la música de cambra és el poema "El rei dels verns", el qual té, com equivalent a un epígraf, la indicació "Schubert"; un text no recollit en les publicacions de la poesia de l'autor, ni el 1947 -ni en les edicions posteriors que en deriven-, ni tampoc en l'edició completa del 2010 (Torres, 1947, 2010a). Sí que s'ha publicat, en canvi, en el facsímil que reprodueix aquell recull mecanoscrit (Torres, 2010c). Aquest petit poema, escrit el 1933, és el següent:

\section{EL REI DELS VERNS}

\section{Schubert}

La sort obscura dels arbres es fa vivent un instant. 
Els verns sorollen les branques

en l'alta nit autumnal.

Brolla un plor de cada fulla.

-plor, o cançó de bressol?

La seva veu és tan pura

com els ulls de l'infant mort.

(Torres, 2010c, p. 6; 2020a) ${ }^{1}$

El poema conté dues estrofes de versos curts, d'art menor. Les dues quartetes són de versos heptasíl $\cdot$ labs, de rima fonètica assonant i encadenada ( $a b a b c d c d$ ), que alterna acabaments de rima accentual femenina o amb paraula plana i de masculina o amb paraula aguda. A la primera estrofa el ritme d'intensitat de les síl labes tòniques cau regularment a les síl·labes segona, quarta i setena. A la segona estrofa el ritme no és regular: a les síl labes primera o segona, tercera o quarta i setena (als tres primers versos), i tercera, sisena i setena (al darrer). Hi trobem tres accents d'intensitat, amb un ritme senzill i melodiós.

La temàtica és de natura. El contingut de la primera estrofa presenta un marc espacial del paisatge, amb els verns, i les seues branques i fulles. El marc temporal és de tardor, respecte a l'estació de l'any, i de nit, pel que fa al moment del dia. La "sort" o destí dels verns s'entrelluca un instant (v. 1-2) en presentar-los com aquells que seran testimonis i acolliran el protagonista. Nit i tardor s'associen i avancen un moment no sols de transformació de la natura sinó d'acabament o mort (v. 3-4), com si el paisatge anunciés el que passarà, després a la fi, amb l'infant.

La segona estrofa introdueix el "plor", mot que apareix dues vegades (v. 5 i 6). La personificació "plor de cada fulla", que pot basar-se en un degoteig d'aigua (d'humitat o de pluja) des de les fulles, queda matisada per la vinculació metafòrica del plor a la "cançó de bressol" (v. 5-6), adient perquè el protagonista és un infant a qui la natura plora i canta per tal d'adormir-lo per sempre. Així la fi fa explícit l'acabament d'aquesta vida amb la referència a l'“infant mort" (v. 8); per tant, es confirma la seua pèrdua de la vida en la natura mentre aquesta el plora i l'acull.

El títol del poema, temàtic, s'agafa d'una composició musical cantada, "Der Erlkönig", i s'esmenta el músic autor de la partitura d'aquesta composició. Aquests dos elements de paratextualitat funcionen a priori d'enllaç intertextual, interdiscursiu o interartístic, per la reproducció exacta del títol traduït i l'explicitació del responsable de la font de partença; tanmateix, el resultat del conjunt del text és un exemple d'hipertextualitat. De fet, són títol i cognom els que connecten de manera directa aquest hipertext amb el Lied D328, Op.1, del mateix títol, de Franz Schubert, que té

${ }^{1}$ Si es contrasta el poema inclòs a Torres (2010c, p. 6) respecte al que apareix al document del Corpus Literari Digital Màrius Torres Mecanoscrits amb poemes solts revisats els anys 1937-1938 (1938), 15r (Torres, 2020a), es pot observar que al primer falta el mot "veu" del vers setè. 
com a text cantat un poema de Johann Wolfgang Goethe, convertits en hipotext. Torres (2020b), com esmenta a la seua carta inèdita del 24 de juliol de 1937, havia llegit Goethe. Però, el seu poema es relaciona amb Goethe a partir de Schubert: sens dubte, és aquesta composició musical la que motiva i suggereix la creació del poema en català, el qual és completament deutor alhora del contingut de la lletra del poeta alemany.

La temàtica del text "Der Erlkönig" de Goethe presenta un pare que cavalca durant la nit i porta el seu fill malalt, amb qui dialoga, mentre aquest petit entrelluca en la seua imaginació el rei dels verns que li apareix i que pretén agafar-lo, amb qui estableix també un diàleg. Aquest rei dels verns representa la mort, que ve a emportar-se'1. El poema acaba amb l'infant morint als braços de son pare. El text de Goethe consta de vuit estrofes de quatre versos, majoritàriament eneasíl·labs o còmputs pròxims, amb rima fonètica regular, consonant $\mathrm{i}$ apariada en cadascuna; la qual cosa facilita un ritme perquè puga ser cantat ${ }^{2}$. Torres comparteix l'estrofa de quatre versos però, en canvi, en té només dues i amb rima fonètica assonant i encadenada. El poema de Goethe és el següent:

\section{DER ERLKÖNIG}

Wer reitet so spät durch Nacht und Wind?

Es ist der Vater mit seinem Kind;

Er hat den Knaben wohl in dem Arm,

Er faßt ihn sicher, er hält ihn warm.

Mein Sohn, was birgst du so bang dein Gesicht?-

Siehst, Vater, du den Erlkönig nicht?

Den Erlenkönig mit Kron und Schweif?-

Mein Sohn, es ist ein Nebelstreif.-

"Du liebes Kind, komm, geh mit mir!

Gar schöne Spiele spiel ich mit dir;

Manch bunte Blumen sind an dem Strand,

Meine Mutter hat manch gülden Gewand."

Mein Vater, mein Vater, und hörest du nicht,

Was Erlenkönig mir leise verspricht?-

Sei ruhig, bleibe ruhig, mein Kind;

In dürren Blättern säuselt der Wind.-

"Willst, feiner Knabe, du mit mir gehn?

Meine Töchter sollen dich warten schön;

Meine Töchter führen den nächtlichen Reihn,

Und wiegen und tanzen und singen dich ein."

2 Vull agrair l'assessorament de Heike van Lawick pel que fa a la mètrica en llengua alemanya. 
Mein Vater, mein Vater, und siehst du nicht dort

Erlkönigs Töchter am düstern Ort?-

Mein Sohn, mein Sohn, ich seh es genau:

Es scheinen die alten Weiden so grau.-

"Ich liebe dich, mich reizt deine schöne Gestalt;

Und bist du nicht willig, so brauch ich Gewalt."

Mein Vater, mein Vater, jetzt faßt er mich an!

Erlkönig hat mir ein Leid getan!-

Dem Vater grausets, er reitet geschwind,

Er hält in Armen das ächzende Kind,

Erreicht den Hof mit Müh' und Not;

In seinen Armen das Kind war tot.

(Goethe, 1990, p. 248-249; Schubert, 2013)

L'abundant presència musical a Música de cambra i altres poemes es confirma, per exemple, al poema desè, intitulat " 2 Lieder" - dos textos no inclosos a l'edició completa de la seua poesia (Torres, 2010a), cadascun dels quals remet a un nom femení ja des del seu títol "Antònia" i "Rosalia". S'hi confirma que l'autor ja des dels anys trenta no sols coneixia Schubert, sinó que resseguia un tipus de composició concreta, els Lieder.

\section{2. "DER TOD UND DAS MÄDCHEN"}

El compositor austríac tractà també, en dues ocasions, el tema de la mort i la donzella. La primera vegada amb el Lied "Der Tod und das Mädchen", D531, Op. 7, número 3, compost el febrer de 1817, i basat en un poema de Matthias Claudius. Es tracta d'una cançó, de dues estrofes de quatre versos de rima consonant encadenada o alternada, en què dialoguen, amb una veu en cada estrofa, la donzella, que vol apartar-se de la mort, i aquesta, la qual li demana que li done la mà per, sense crueltat, fer-la dormir definitivament entre els seus braços. El text "Der Tod und das Mädchen" és el següent:

\section{DAS MÄDCHEN:}

Vorüber! Ach, vorüber!

Geh, wilder Knochenmann!

Ich bin noch jung! Geh, Lieber,

Und rühre mich nicht an.

DER TOD:

Gib deine Hand, du schön und zart Gebilde!

Bin Freund, und komme nicht, zu strafen. 
Sei gutes Muts! Ich bin nicht wild,

Sollst sanft in meinen Armen schlafen!

(apud Claudius, 2020; Schubert, 2008)

La segona vegada que el compositor va tornar sobre aquest tema fou l'any 1824 , quan es trobava malalt: llavors acabava el seu conegudíssim quartet de corda número 14, en re menor D810, intitulat també "Der Tod und das Mädchen", on recrea de nou, per evocació musical i ara sense text, el tema de la visita de la mort a la jove donzella. La gran tensió i el conflicte entre ambdues, entre l'inexorable destí i les ganes de viure, l'expressava intensament el compositor sobretot en el dramatisme del llarg segon moviment, l'andante com moto, amb les perfectes i suggestives variacions sobre el tema dominant, tema que amplia considerablement la melodia respecte al que era la de l'inici del seu Lied anterior. El tempteig de les possibilitats expressives, en forma de variació, permet avançar en la construcció de la composició, amb intensitat, riquesa i gravetat.

Màrius Torres té un poema intitulat "La Mort i el Jove" (per tant, canviant la protagonista donzellla pel jove), del 14 d'agost de 1938, vinculable, pel paratext, a aquestes dues composicions de Schubert; i com a hipertext, sobretot a la primera, el Lied, a partir del text del qual -i des de la interrelació de gèneres artístics- s'hi fa una transposició o transformació seriosa. Cal subratllar que tant en la primera versió manuscrita autògrafa com també les mecanoscrites ${ }^{3}$ de "La Mort i el Jove", aquest poema constava de dos sonets (I i II. "Paraules de la Mort") cadascun dels quals remet a la intervenció de la veu d'un dels personatges: el primer, la del jove; i el segon, la de la mort, com també passa a la lletra de Claudius i al Lied de Schubert, els quals funcionen com a hipotext. En la primera edició del poema del 1947, els dos sonets van perdre la seua numeració romana i es van publicar de forma independent: els poemes numerats com a 37, que manté el títol "La Mort i el Jove", i el següent, el 38, intitulat "Paraules de la Mort" (Torres, 1947), respectivament. Aquesta mateixa separació també s'ha mantingut a les edicions posteriors (Torres, 2010a, p. 78-79). Tot seguit restituïm la numeració dels dos sonets (I i II) dins un únic poema ("La Mort i el Jove"), ja que, de fet, en són dues parts.

El sonet I, amb un títol que modifica el de Schubert, és el següent:

\section{LA MORT I EL JOVE (I)}

Mai una boca ardent no assedegà la febre com la meva, esperant respirar pel teu pit.

\footnotetext{
${ }^{3}$ Així es pot comprovar als documents del Corpus Literari Digital Màrius Torres Esborranys $i$ versions conservats per Mercè Figueras (1942), 77r i 77v, i Obra poètica de Màrius Torres primera còpia completa (1942), 31 (Torres, 2020a).

${ }^{4}$ La restitució de la numeració en els sonets és nostra, no de l'edició citada.
} 
Mai no foren tan grans uns ulls en la tenebra com ara els meus, Amarga, que et miren fit a fit!

Res, mai, ni l'invencible engany de l'esperança, no em feia tremolar davant de l'infinit.

Però ara el teu fred fa comprendre, enfonsant-se, quina cosa tan fràgil es torna un esperit.

Morir... Si almenys pogués arrabassar i endur-me tot el que he malgastat, vivint entre la xurma, d'amor, d'ambicions, de treballs, d'ideals!

Pesa poc la meva ànima, nua en ella mateixa. ¿No li serà comptat el pes d'allò que deixa vivent, entre les vostres mans de foc, Immortals?

(Torres, 2010a, p. 78)

El sonet d'alexandrins té rima fonètica consonant ( $A B A B C B C B D D E F F E$ ), encadenada en els quartets (alternant la rima accentual femenina i masculina) i apariada en els tercets (femenina), enllaçant els darrers de cadascun (masculina). La Mort visita el Jove malalt per endur-se'l (cal fixar-se que l'autor escriu les designacions dels protagonistes amb lletra inicial majúscula). Aquest es dirigeix en primera persona a la mort, qualificada i anomaneda com "Amarga". La boca ardent i els ulls de tenebra observen i esperen la mort, com estableix l'estrofa primera (v. 1-4). L'esperança de sobreviure és un engany $\mathrm{i}$ el fred de la fi de la vida mostra la fragilitat de l'esperit humà, segons consta a la segona (v. 5-8). Als tercers, es medita sobre el que comporta morir: deixar-ho tot (v. 9-11) i, amb l'ànima nua, lliurar-se a les mans de foc, que consumiran el cos convertint-lo en cendra, però que són unes mans que poden permetre el pas a la immortalitat perquè són "Immortals" (v. 12-14).

El sonet II s'intitula "Paraules de la Mort". Ara és la mort qui respon al jove (com també passava a les dues parts del text del Lied):

\section{(II) PARAULES DE LA MORT}

Tu, jove moribund que ara m'has dit Amarga, amargs són els teus llavis per comprendre el meu gust! Si em trobessis al fons d'una vida més llarga, quan em diries Dolça també fores injust.

El meu sabor és fet de milions de vides que ha apagat el meu bes, obscur en la fredor: astres, ànimes, déus. I ara que ets tu que em crides, seré un instant amarga de la teva amargor... 
Gran ocell de silenci, indiferent i muda germana de la nit, sobre la carn vençuda el meu vol és profund i pàl·lid, però breu.

Calmo, amb dits de repòs, la seva última alarma; però, més que l'angúnia, m'allunya d'aturar-me la llum de l'alba de l'àngel que ve darrera meu.

(Torres, 2010a, p. 79)

Aquest segon sonet és d'alexandrins de rima fonètica consonant ( $A B A B C D C D$ $E E F G G F$ ), encadenada en els quartets (alternant rima accentual femenina i masculina) i apariada en els tercets (femenina), enllaçant els darrers de cadascun (masculina). Segueix el mateix model formal que el sonet anterior.

Es presenten les paraules de resposta de la mort, com el títol clarament indica, la qual cosa enllaça amb claredat amb el sonet anterior en referir el $t u$ com "jove moribund" i el jo com aquell que havia estat qualificat com "Amarga". El jove té una llavis amargs per la vivència de trobar-se a la fi de la seua vida (primer quartet, v. 1-4). En contrast, la mort parla del seu sabor pel bes donat a les vides que ha apagat i que ara serà amarg per al jove (segon quartet, v. 5-8). La mort es vincula al silenci i a la nit, el seu vol és breu quan cau sobre la "carn vençuda" de qui ha de morir (primer tercet, v. 9-11); però així com després de la nit arriba la llum de l'alba, la mort va seguida, després, per l'àngel (darrer tercet, v. 12-14), la qual cosa planteja la fi de la vida com un trànsit breu a un altre àmbit d'immortalitat de l'ànima (en sintonia amb el darrer mot del primer sonet, "Immortals").

\section{ADVERBIS PER A "STÄNDCHEN"}

Entre "El rei dels verns" i "La Mort i el Jove", l'any 1936 el poeta de Lleida havia tingut present Schubert al poema "Adverbis de Schubert", un text desestimat en la primera edició del 1947 però, tanmateix, inclòs en les seues tries de textos compreses entre 1937 i 1941 (Torres, 2020a). Al títol hi ha la referència explícita del cognom, un altra manera de reenviar (Samoyault, 2001, p. 35), des del paratext, al compositor. Reproduïm el poema:

\section{ADVERBIS DE SCHUBERT}

Per a Mercè Figueras

És en un prat, rubert de margarides, amb arbres blancs, acàcies o til·lers, que joves veus, per les ombres florides diuen, només amb un sospir,-després...? 
O és en una boscúria, una nit clara,

ben prop del cant dels rossinyols germans, que veus antigues van resant encara més llangorosament que abans -abans...?

Per quins neguits, per quins somnis s'escola, ombres d'amor, el vostre dolç desmai? Les cançons van per l'aire que tremola d'un-sempre! pàl·lid com si fos un -mai.

(Torres, 2010a, p. 188)

Les tres estrofes són quartets de decasíl·labs amb rima fonètica consonant encadenada ( $A B A B C D C D E F E F)$, la qual alterna acabaments de rima accentual femenina i masculina. Les dues primers estrofes, quasi paral·leles, presenten, en un marc paisatgístic de natura, una alternança entre el que diuen les "joves veus", situades en un prat florit (v. 1-4), i el que resen les "veus antigues", situades en la boscúria i la nit (v. 5-8). Unes veus remeten a la joventut $i$ unes altres a la vellesa, amb la seua provisionalitat, com l'adverbi "encara" apunta. Les primeres indiquen el futur immediat, l'esdevenidor, mitjançant l'adverbi final "després”, mentre que les segones apunten al passat mitjançant l'adverbi “abans”. És la darrera estrofa (v. 9-12) aquella que reuneix el parlant líric i el vós interlocutor i assenyala com la seua estima ("ombres d'amor", v. 10) té contradiccions com els dos adverbis del darrer vers contrasten i contraposen: "sempre" i "mai" (v. 12).

Els quatre adverbis temporals ("després", "abans", "sempre", “mai”), situats tres d'ells a la fi de cadascuna de les estrofes i tots quatre tipogràficament entre un guionet $i$, excepte el darrer, un signe d'interrogació o d'exclamació, remeten al primer mot del títol, adverbis de sentits contraposats que apunten al passat $i$ al futur, a la permanència i a l'absència. Al títol aquests es vinculen a Schubert: potser cal relacionar el músic amb el mateix poeta i el vós és un interlocutor ficcional que remet a Mercè Figueras, a qui dedica el poema i a qui el poeta dirigeix la seua reflexió poètica. Convé recordar que a la carta del 21 de juny de 1937, posterior al poema, Figueras vinculava Torres amb Schubert: "parlaràs en vers amb la fluïdesa d'un Schubert" (Torres \& Figueras, 2018, p. 86-87). Una primera versió mecanoscrita del poema havia tingut un títol parcialment diferent: "Paisatges de Schubert".

Aquesta al·lusió al compositor, en canvi, no apareix explícita en un altre poema de l'autor, l'intitulat "Mai", del 1937, text que enllaça amb aquest anterior i alhora connecta directament amb el poeta francès Alfred de Musset, que havia estat llegit, traduït i musicat per l'escriptor de Lleida (Torres, 2010b). Els tres poemes de Musset versionats en llengua catalana foren "Jamais" (text del 1830, traduït l'agost del 1933), “Chanson" (del 1840, traduït també l'agost del 1933), i “A M.V.H. Sonnet” (del 1843, traduït el febrer del 1936). Les cronologies de la realització d'aquestes tres traduccions són coetànies als textos que hem vinculat a Schubert dels anys 1933 i 1936. A més, 
pel que fa a la connexió entre tots dos escriptors, cal dir que el sonet "J'ai dit à mon coeur", de Musset, és l'hipotext del sonet hipertext de Torres "He dit al meu cor...", escrit el 1937 (Torres, 2010a, p. 39).

Ara la relació entre Torres i Schubert s'enriqueix des de la intertextualitat amb Alfred de Musset. Al poema ja revisat "Adverbis de Schubert", Torres havia tingut present el sonet de Musset "Jamais": ambdós poemes esmenten Schubert (el primer, al segon vers; i el segon, al títol) i fins i tot connecten per la recurrència de l'adverbi "mai" (respectivament, com primer mot del vers primer i com últim mot de darrer vers).

El 10 de març de 1937 Torres data un poema autògraf de tres textos intitulat "Adverbis de temps", dedicat a Esperança Figueras, la germana de Mercè Figueras 5 . Els tres textos numerats se subtitulen I. "Encara", II. "Llavors" i III. "Mai": és a dir, tres adverbis de temps. En reelaboracions posteriors, el tercer text va quedar com un poema independent i ha estat recuperat en l'edició completa de 2010. En aquest Torres tornava sobre el "Jamais", de Musset, ja que té com epígraf "Jamai, avez-vous dit...", és a dir, els mots inicials del poema francès. Si al sonet Musset esmentava, com diu al segon vers, que "Résonnait de Schubert la plaintive musique" (v. 2), al de l'escriptor català el músic no s'hi refereix però, tanmateix, hi ha mots d'àmbit musical com ara "tenor", "concertants", "àries" o "cant". Reproduïm tot seguit els dos poemes:

\section{JAMAIS $^{6}$}

Jamais, avez-vous dit, tandis qu'autour de nous

Résonnait de Schubert la plaintive musique;

Jamais, avez-vous dit, tandis que, malgré vous,

Brillait de vos grands yeux l'azur mélancolique.

Jamais, répetiez-vous, pâle et d'un air si doux

Qu'on eût cru voir sourire une médaille antique.

Mais des trésors secrets l'instinct fier et pudique

Vous couvrit de rougeur, comme un voile jaloux.

Quel mot vous prononcez, marquise, et quel dommage!

Hélas! je ne voyais ni ce charmant visage,

$\mathrm{Ni}$ ce divin sourire, en vous parlant d'aimer.

${ }^{5}$ Així es pot comprovar als documents del Corpus Literari Digital Màrius Torres Esborranys $i$ versions conservats per Mercè Figueras (1942), 47v, 48r, 49v (Torres, 2020a).

${ }^{6}$ Aquesta és la traducció que en va fer Torres: JAMAI/ Jamai, em vàreu dir, mentre que vora nostre/ de Schubert ressonava planyívola tonada./ Jamai, em vàreu dir, però a desgrat vostre/ teníeu un esclat d'enyor a la mirada.// Repetíreu, jamai, amb un parlar tan dolç/ com el perfum subtil d'una vella medalla/ i l'instint del secret us enrogí gelós,/ com un vel que coneix les joies que embolcalla.// Quin mot desolador, marquesa, i quina pena/ que jo no hagués trobat aquesta faç serena/ ni aquest diví somrís en parlar-vos d'amor.// Teniu els ulls menys clars que no l'ànima bella/ $i$, àdhuc aquell moment, només pensava en ella,/ $i$ en la inutilitat del vostre cor en flor (Torres, 2010b, p. 108-109). 
Vos yeux bleus sont moins doux que votre âme n'est belle.

Même en les regardant, je ne regrettais qu'elle,

Et de voir dans sa fleur un tel coeurs se fermer.

(apud Torres, 2010b, p. 108)

Es tracta d'un sonet de temàtica amorosa, escrit en versos alexandrins amb rima fonètica encadenada en quartets i apariada entre els dos primers versos de cada tercet, rimant els darrers versos entre ells ( $A B A B C D C D E E F G G F)$. El poema presenta, sobretot en els quartets, la negativa o rebuig del vós femení al jo poètic masculí, mentre s'escolta una música de Schubert. Els tercets tracten la percepció del jo poètic, a partir de l'adverbi desencoratjador que intitula el poema, qui considera que no ha sabut transmetre el seu amor a l'estimada d'ànima bella.

“Mai" té ben present aquest sonet anterior de Musset, on s'esmentava Schubert:

MAI

Jamais, avez-vous dit...

A. de Musset, 1840

Quin escenari, quines lluminàries,

quina dama, Déu meu, i quin tenor!

-Mai, em diguéreu, com si el meu amor

també parlés amb concertants $i \mathrm{amb}$ àries.

Per què, Senyora, aquest terrible mot

que gela el foc i barra el pas a tot

llevat dels versos i del suïcidi?

Tanqueu els ulls i us en torneu al cant.

I, tanmateix, aquest segle galant, guarda sota el coixí els llibres d'Ovidi.

(Torres, 2010a, p. 203)

Com s'ha assenyalat, aquest poema prové de la reducció del tercer text de l'autògraf "Adverbis de temps", on llavors era un sonet. Torres en la versió definitiva modifica el primer quartet i suprimeix el segon. Els dos quartets de l'autògraf original eren així:

-Mai, em diguéreu, mentre un bell tenor

en l'escenari ple de lluminàries

els seus neguits explicava en les àries

d'una divina música d'amor.

-Mai, em diguéreu, veient que us mirava

amb una expressió de decencís. 
-Mai, repetíreu. Però amb un somrís

de comiat, quan l'òpera acabava.

Com a versió definitiva queden deu versos decasíl·labs agrupats en un quartet $i$ dos tercets, amb rima fonètica consonant $i$ creuada al quartet i rima apariada entre els dos primers versos de cadascun dels tercets i rima entre els altres dos tercets $(A B B A$ $C C D E E D$ ). El quartet inicial (v. 1-4) també parteix d'una música escoltada, com en Musset, en qui aquella era de Schubert. Ara, en canvi, sense referir cap compositor s'hi esmenten dama $i$ tenor amb concertants $i$ àries. La música és l'escenari de partença, l'acompanyament del "mai" del títol i de la resposta del vós al jo. És l'amor del jo el que s'emmarca amb la música inicial que sedueix i captiva: "divina música d'amor", deia el quart vers de la primera versió.

La segona estrofa (v. 5-7) reprodueix la negativa de la "Senyora" ("marquesa" en el poema de Musset, també en el primer vers del primer tercet) a l'amor del jo, el qual, segons el text, només té com a alternatives, per tal d'afrontar la situació de no correspondència, l'escriptura o el suïcidi. La darrera estrofa (v. 8-10) situa el vós amb el somni i la imaginació en el "cant", és a dir, l'escriptura o la composició, la ficció i l'art, la qual cosa enllaça amb l'inici del poema, la dama i el tenor. Potser la dama representava el vós i el tenor que canta era un correlat del jo oferint un cant d'amor.

Quan Màrius Torres i Mercè Figueras es reunien al sanatori, de vegades ell interpretava música amb el piano mentre ella cantava. De fet, a la carta del 10 de juliol de 1937, va escriure: "Et sento cantar la Serenata de Schubert; series tan bona, quan m'escriguis, de transcriure'm la lletra? No la puc recordar i tinc ganes de cantar-la jo també" (Torres, 2020b). S'hi refereix al Lied "Ständchen", D957, amb lletra del poeta Ludwig Rellstab, compost el darrer any de la vida del músic. En aquest, de cinc estrofes de quatre versos, que alternen la rima fonètica consonant de manera encadenada, el parlant, enamorat, implora al $t u$, la "Liebchen" ("marquise" en el poeta francès o "Senyora" en el català), que l'escolte i vinga al seu costat pel dolor que li causa l'amor. Probablement, aquest Lied era "la plaintive musique" de Schubert del segon vers de Musset, traduit per Torres, qui va tenir alhora tots dos presents. I potser el "Jamais" o el "Mai" d'ambdós poetes siguen dues respostes poètiques al Lied de Schubert, a la petició de reunir-se (del jo a l'estimada) que el baríton cantava amb la següent lletra de Rellstab:

\section{STÄNDCHEN}

Leise flehen meine Lieder

Durch die Nacht zu dir;

In den stillen Hain hernieder,

Liebchen, komm zu mir! 
Flüsternd schlanke Wipfel rauschen

In des Mondes Licht,

Des Verräters feindlich Lauschen

Fürchte, Holde, nicht.

Hörst die Nachtigallen schlagen?

Ach! Sie flehen dich,

Mit der Töne süssen Klagen

Flehen sie für mich.

Sie verstehn des Busens Sehnen,

Kennen Liebesschmerz,

Rühren mit den Silbertönen

Jedes weiche Herz.

Lass auch dir die Brust bewegen,

Liebchen, höre mich,

Bebend harr ich dir entgegen!

Komm, beglücke mich!

(Schubert, 1986)

El text del Lied es conserva en llengua catalana en versió autògrafa de Torres dins el seu Quadern de notes particulars i cites de diversos autors (Torres, 2020c). El trancrivim (amb alguna regularització):

\section{SERENATA}

\section{Música de Schubert}

Lleus, mos cants, vers tu fan via dins la quieta nit:

ja tot callat al prat, aimia, vine prest amb mi.

Fan murmuri dolç els arbres, clar de lluna és tot; que un traidor ens escolti ara, oh! no tinguis por! (bis)

Sents els rossinyols com canten?

Precs et fan així amb llur dolça veu s'exclamen bo i pregant per mi.

Ells comprenen tota l'ànsia tot el mal d'amor 
fort commouen llurs passades

cada tendre cor. (bis)

Deix' també que jo et commogui,

vine, amada, amb mi, ai! t'enyoro i tot tremolo.

Vine, fes-me feliç. (bis)

\section{FINALE}

Màrius Torres va madurar literàriament entre els anys 1933 i 1938, en un moment d'evolució poètica i de consolidació, acompanyat per les composicions de Schubert i els versos de les lletres dels seus Lieder. Les distintes formes de transtextualitat i les interrelacions artístiques són evidents i rellevants en la seua escriptura d'aleshores, la qual es nodria tant de les lectures literàries com de les audicions i interpretacions musicals -fins i tot de vegades, com s'ha vist, elaborava textos seus a partir de la reescriptura. Per a ell, la música no sols embellia el ritme dels seus versos, sinó que sovint els inspirava; i, a més, aquests se n'aprofitaven. Perquè la música, com la poesia, era considerada una activitat $i$ una experiència de potenciació de la sensibilitat, d'aprofundiment en l'interior i d'enriquiment espiritual.

\section{AGRAÏMENTS}

Aquest treball s'inscriu dins el projecte d'investigació del Ministerio de Ciencia e Innovación FFI2017-86542-P titulat La literatura de segundo grado: las relaciones hipertextuales en la literatura catalana desde el "Modernisme" hasta 1939. Més informació sobre l'activitat del grup investigador a: http://www.uv.es/ironialitcat/. 


\section{REFERÈNCIES BIBLIOGRÀFIQUES}

Boixareu, M. (1968). Vida i obra de Màrius Torres. Barcelona: Selecta.

Bou, E. (1989). Poesia i sistema. La revolució simbolista a Catalunya. Barcelona: Empúries.

Carbó, F. (1995) "Couperin a l'hivern": una interpretació musical en la poesia de Màrius Torres. Dins

N. Garolera (ed.). Textos literaris catalans. Lectures i interpretacions, II (p. 149-160). Barcelona: Columna.

Carbó, F. (2020). “Enamouré d'un nom”. La primera cançó a Mahalta de Màrius Torres. Dins C. Gregori, J. Malé \& G. López-Pampló (eds.). Reescriptures literàries (p. 605-629). Barcelona: Publicacions de l'Abadia de Montserrat.

Claudius, M. (2020). Der Tod und das Mädchen. Recuperat de https://www.oxfordlieder.co.uk/song/2616.

Genette, G. (1982). Palimpsestes. La littérature au second degré. París: Seuil.

Genette, G. (1987). Seuils. París: Seuil.

Goethe, J. W. (1990). Der Erlkönig. Dins Heinz Nicolai (ed.). Goethes Gedichte in zeitlicher Folge (p. 248-249). Frankfurt am Main: Insel [Publicat originalment el 1982].

Klein, I. (2017). Màrius Torres i la música. València: Universitat de València [Treball de Final de Màster dirigit per F. Carbó].

Klein, I. (2018). Edició i anàlisi de les composicions musicals de Màrius Torres. Dins J. Camps Arbós, I. Farré Vilalta \& J. R. Veny-Mesquida (eds.). La ciutat d'ideals que voliem bastir. Màrius Torres i la literatura del seu temps (p. 217-240). Lleida: Pagès editors \& Aula Màrius Torres.

Koralova, V. (2008). The Artistic Phenomenon as an Intermedial Structure in the Arts. Applied Semiotics, 20. Recuperat de https:/www.questia.com/library/journal/1G1-181815505/the-interartistic-phenomenon-as-an-intermedial-structure.

Kristeva, J. (1969). Sèméiôtikè. Recherches pour une sémanalyse. París: Seuil.

Lleó, M. (2018). Màrius Torres: entre el barroc i el lied. Dins J. Camps Arbós, I. Farré Vilalta \& J. R. Veny-Mesquida (eds.). La ciutat d'ideals que voliem bastir. Màrius Torres i la literatura del seu temps (p. 241-254). Lleida: Pagès editors \& Aula Màrius Torres.

Prats, M. (1986). Màrius Torres. L'home i el poeta. Barcelona: Edicions del Mall.

Prats, M. (2010). Introducció. Dins Màrius Torres, Poesies (p. 11-25). Lleida: Pagès editors.

Rabaseda i Matas, J. (2010). I abans del poema, una música. L'Avenç, 253, 68-69.

Sales, J. (2014). Cartes a Màrius Torres. Barcelona: Club editor.

Samoyault, T. (2001). L'intertextualité. Mémoire de la littérature. París: Éditions Nathan.

Schubert, F. (1986). Schwanengesang. D957. Capriccio [CD interpretat per Siegfried Lorenz \& Norman Shetler].

Schubert, F. (2008). The Wanderer. Lieder and fragments. EMI [CD interpretat per Ian Bostridge \& Leiv Ove Andsnes].

Schubert, F. (2013). Erlkönig. Harmonia mundi [CD interpretat per Matthias Goerne \& Andreas Haefliger].

Segre, C. (1982). Intertestuale-interdiscorsivo. Appunti per a una fenomenologia delle fonti. Dins F. Brioschi, C. Di Girolamo \& I. Paccagnella (eds.). La parola ritrovata (p. 15-28). Palerm: Sellerio.

Torres, M. (1947). Poesies (ed. de J. Sales). Coyoacán: Quaderns de l’Exili.

Torres, M. (2010a). Poesies de Màrius Torres (ed. de M. Prats). Lleida: Pagès editors.

Torres, M. (2010b). Versions de poesia europea (ed. de P. Ballart \& J. Julià). Lleida: Pagès editors.

Torres, M. (2010c). Reculls de poemes 1927-1936. Lleida: Pagès editors \& Aula Màrius Torres [Edició facsímil].

Torres, M. (2020a). Corpus Literari Digital de la Càtedra Màrius Torres. Recuperat de www.catedramariustorres.udl.cat/materials/. 
Torres, M. (2020b). Correspondència emesa per Màrius Torres: cartes a Mercè Figueras i a Joan Sales. Recuperat de http://repositori.udl.cat/handle/10459.1/27.

Torres, M. (2020c). Quadern de notes particulars i cites de diversos autors. Recuperat de http://repositori. udl.cat/handle/10459.1/27.

Torres, M. \& Figueras, M. (2018). Cartes a Mahalta. Barcelona: Club editor. 